\title{
Eyebrows contact dermatitis miming angioedema
}

\section{Imane Alouani ${ }^{1}$, Siham Dikhaye ${ }^{1,2}$, Nada Zizi ${ }^{1,2}$}

${ }^{1}$ Department of Dermatology, Mohammed 6 University Hospital of Oujda - Medical School of Oujda, Oujda, Morocco, ${ }^{2}$ Laboratory of Epidemiology, Clinical Research and Public Health, Medical School of Oujda, Mohammed First University, Oujda, Morocco

Corresponding author: Dr. Imane Alouani, E-mail: alouani01@gmail.com

A 27-years-old lady was admitted to the emergency department of our institute for bilateral pruritic periorbital swelling. She had no prior history of eczema or any allergic reactions. Three days before her admission, she had her brows tinted by with a black eyebrow dye containing para-phenylenediamine (PPD). Examination revealed an erythematous papulovesicular, partially crusted lesion on both eyebrows (Fig. 1). A diagnosis of a contact dermatitis was made and a course of topical desonide ointment once a day for one week resolved the eruption.

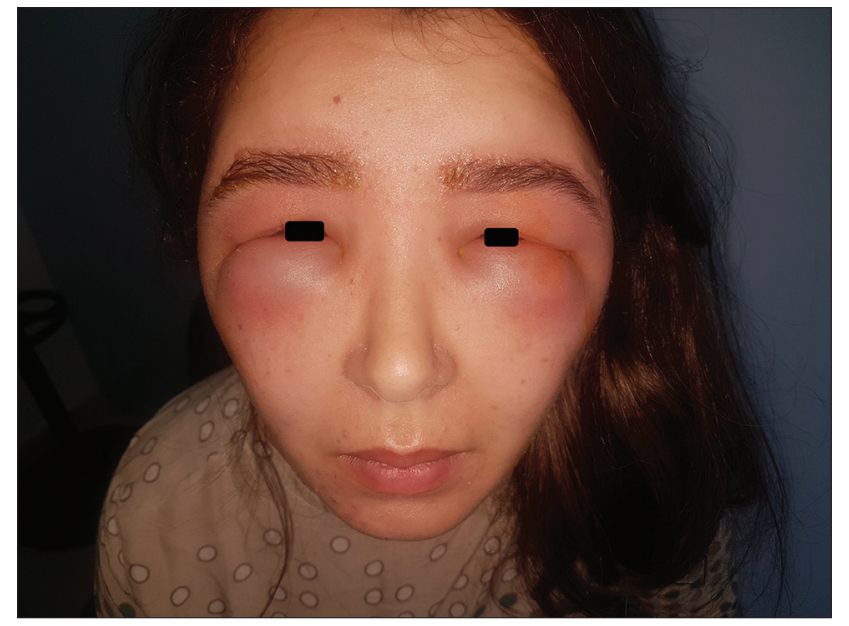

Figure 1: Bilateral pruritic periorbital swelling with papulovesicular crusted lesion of the eyebrows.
Contact dermatitis from PPD miming angioedema has rarely been reported in the literature $[1,2]$. The skin lesions have been reported to be erythema, erythema multiforme-like eruption, bullous contact dermatitis, pruritic, edematous, erythematous scaly patches and plaques or vesicular lesions [1].

\section{Consent}

The examination of the patient was conducted according to the Declaration of Helsinki principles.

\section{REFERENCES}

1. Demirci GT, Altunay IK, Atis G, Kucukunal A. Allergic contact dermatitis mimicking angioedema due to paraphenylendiamine hypersensitivity: a case report. Cutaneous and Ocular Toxicology, 2012;31:250-2

2. Sánchez-Guerrero IM, Huertas AJ, López MP, Carreño A, Ramírez M, Pajarón M. Angioedema-like allergic contact dermatitis to castor oil. Contact Derm. 2010;62:318-9.

Copyright by Imane Alouani, et al. This is an open-access article distributed under the terms of the Creative Commons Attribution License which permits unrestricted use, distribution, and reproduction in any medium, provided the original author and source are credited.

Source of Support: Nil, Conflict of Interest: None declared. 